\title{
Crime victimization: its extent and communication
}

\author{
Paul Wiles and Jon Simmons \\ Home Office, London, UK \\ and Ken Pease \\ University of Huddersfield, UK
}

[Received April 2002. Revised December 2002]

\begin{abstract}
Summary. The criminal justice contexts are identified in which understanding and communicating risks are important. The paper is thereafter exclusively concerned with the probability of crime victimization classified by person and location. Examples of crime risks derived from the British Crime Survey are provided, with instances of where concern about crime diverges from risks of crime. Caution is advocated about seeking to reduce the fear of crime by reassurance. The high levels of concentration of crime by location are noted, together with the fact that particular individuals and households are repeatedly victimized, enabling the prioritization of crime-reductive resources after a crime has taken place. The paper concludes that an emphasis on how the supply of criminal opportunities may be regulated heralds a more systematic approach to the distribution of unavoidable hazard among citizens.
\end{abstract}

Keywords: Crime; Crime displacement; Fear of crime; Repeat victimization

\section{Introduction}

There are at least four criminal justice contexts in which understanding and communicating risks are important. In the first, the probability of crime victimization classified by location and person needs to be established, whether for prevention or detection. In the second, the chance that someone will embark on a criminal career (and the social and familial determinants of that) is of clear importance for social, health and education policy. Third, the risk that an offender will commit crime of a particular type in the future is of concern for sentencing law and discretionary release decisions. In the final case, the likelihood that a particular offender is responsible for a particular unsolved crime has generated a literature on offender profiling: a technique whose worth remains contentious. In this paper we shall concentrate exclusively on the first of these categories, the risk of suffering crime that each of us bears as we go about our lives. This was a hard choice, given that the second and third kinds of work have yielded important insights (those interested may care to read Wikstrom and Loeber (2000) as an example).

\section{The extent and distribution of crime victimization}

The predictability of crime at a particular place and time varies. In the limiting case, police 'sting' operations set up situations where the probability of crime comes close to 1 . If a crime does not occur, the operation is a failure. Drug and prostitution markets rely on predictabilityotherwise how would customers know where to go? The fact that residents know where and

\footnotetext{
Address for correspondence: Ken Pease, 19 Withypool Drive, Stockport, SK2 6DT, UK. E-mail: kenpease@aol.com
} 
when drugs are dealt but the market survives causes them much frustration. Those feelings are typically vented against the police and reveal the gap between knowing where a crime occurs and fulfilling evidentiary requirements for a court.

Volume crime is the term that is used to encompass those types of offence whose frequency is such as to mean that, taken together, they account for the bulk of crime suffered. Burglary, assaultive crime (including robbery), sexual crimes and theft (including theft of and from motor vehicles) are the commonly used subcategories of volume crime. For most such crime, the likelihood of falling victim varies enormously by a wide range of area, household and personal characteristics.

Table 1 illustrates the range of victimization levels by household characteristics, and derives from data captured by the 2001 British Crime Survey (BCS). This is a household survey yielding estimates of crime suffered, whether or not reported to the police (see Kershaw et al. (2001) and Simmons (2002)). The BCS has for 20 years yielded data to complement recorded crime data. It has interviewed randomly selected household members aged 16 years or over, enjoying high response rates. In 2001-2002, 33000 interviews were conducted. Details of sampling, weighting, response rates and other aspects of the BCS are available from the technical reports accompanying each sweep. The most recent of these is published as Bolling et al. (2002). The major limitation of the BCS is its exclusion of crime against business, and against children.

Table 1 shows that the likelihood of suffering a burglary varies enormously, from around 2 in 100 for pensioner households to around three or four times that rate for the youngest households, single parents and the unemployed. Similar ranges of risk are evident in both vehicle-related theft and personal violence. For example the probability that a household whose head is under 25 years old suffers vehicle-related theft is around a quarter of that of a household headed by someone over 60 years old (Kershaw et al. (2001), Table A4.7). Not shown in Table 1 but of considerable practical importance is the overlap between offending and victimization (see for example Mayhew and Elliott (1990)).

Fig. 1 shows the cumulative proportion of recorded robberies in England and Wales accounted for by each crime partnership (local authority) area. 20 local authority areas account for around a half of all robberies in England and Wales. As we might expect, these tend to be the

Table 1. Percentage of household victims of burglary with entry or attempted burglary once or more in 2000 , by selected household types †

\begin{tabular}{|lc|}
\hline & Type of household \\
\hline & \\
\hline & \\
Head of household aged 16-24 years & 4.6 \\
Head of household aged 25-44 years & 4.2 \\
Head of household aged $\geqslant$ 60 years & 2.2 \\
Single-adult household with children & 7.9 \\
Two- or more adult households with children & 3.4 \\
Households with no children & 3.8 \\
Head of household in employment & 3.3 \\
Head of household economically inactive & 3.9 \\
Head of household unemployed & 7.0 \\
All households & 3.4 \\
\hline
\end{tabular}

$\dagger$ The results are based on responses of 8985 respondents, one per household. A more detailed breakdown can be found in Kershaw et al. (2001), Table A4.3. 


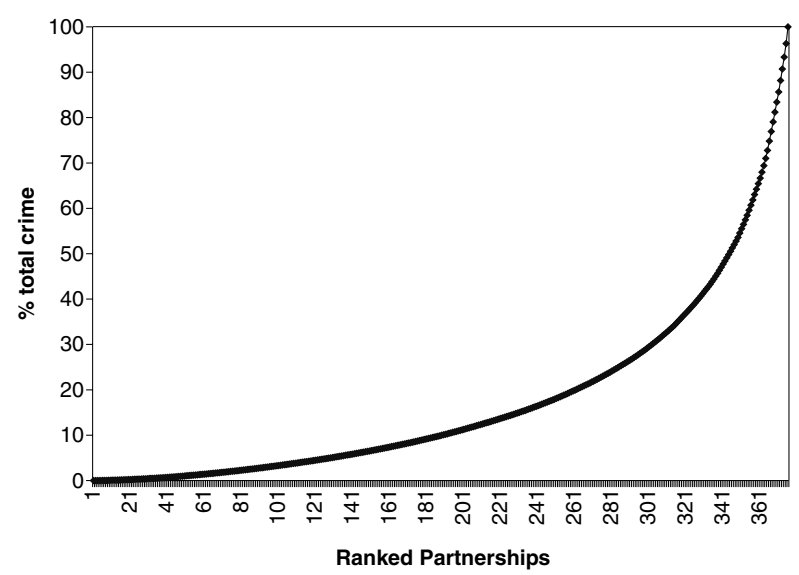

Fig. 1. Cumulative distribution of robbery by crime prevention partnership area, England and Wales

larger inner city areas. Two-thirds are in London. If the Government wishes to attack the robbery problem, then these are the places where there is most to be gained. Obviously, location (Kershaw et al. (2001), Table A4.16) within local authority areas, together with personal (Kershaw et al. (2001), Table A4.12) and household (Kershaw et al. (2001), Table A4.13) characteristics also contribute to the level of risk.

\section{Hazard and perceived risk}

There is a mismatch between an individual's expected probability of falling victim to crime and his or her actual probability of suffering that misfortune. The latest BCS reveals that it is the wealthy who appear most vulnerable to being attacked by strangers $-2.1 \%$ of people with a household income of $£ 30000$ or more were victims once or more, compared with $1.6 \%$ of those with an income of less than $£ 5000$ and $0.9 \%$ for those earning between $£ 5000$ and $£ 10000$ (Kershaw et al. (2001), Table A4.13). Yet it is the most victimized group which feels least at risk from attacks by a stranger (Kershaw et al. (2001), Table A5.4), with only 8\% feeling fairly or very likely to become a victim in the next year, compared with $14-15 \%$ for the lower income groups. One variation on the expectation of victimization is fearfulness about it. There is often a mismatch between the probability of suffering crime and the fear of crime, with the elderly having by far the lowest rate of victimization and yet worrying about crime about as much as, if not more than, everyone else (Kershaw et al. (2001), Table A5.9). 9\% of men and 33\% of women over 60 years of age feel very unsafe walking alone in their own area after dark, contrasted with only $3 \%$ of men and $15 \%$ of women under 30 years of age. However, the relative risk of being a victim of an attack by strangers or a mugging is almost the inverse of feeling unsafe (Kershaw et al. (2001), Table A4.12). Around $8.5 \%$ of young men were victims of attacks by strangers according to the BCS, compared with $1.9 \%$ of young women. The elderly suffer such attacks at a rate of less than $0.1 \%$.

This low level of victimization of the elderly may be partly due to the precautions which they take, e.g. by not walking out alone at night. It may be that their victimization per unit time exposed to risk reflects the accuracy of their perception. Among respondents of all ages, those who were victims of burglaries and violent crime tend to be more fearful of being alone at home at night (over twice as many feel unsafe compared with those who were not victims; Kershaw et al. (2001), Table A5.15) and believed that they were more likely to be victims in 
the next year (Kershaw et al. (2001), Table A5.5). One factor in the generation of fear may be the consequences of risk, which may be more severe for the elderly-and, since women outlive men, the elderly woman may be more likely to have to fend for herself in the aftermath of a crime. Other factors may include the image of the crime that is suffered in comparison with the reality. It is interesting that those who have suffered a crime tend to rate its seriousness lower than those who have not suffered it, suggesting that the stereotypical crime, i.e. the crime held in imagination by those who have not suffered it, is more serious than the average crime of that type (Pease, 1988).

The Association of Chief Police Officers has advocated a 'reassurance agenda'. Although such an approach has much to commend it, the simple divergence of risk and fear is not a sufficient basis for providing reassurance. The anticipated effect of crime depends on individual circumstances which may be very specific. A general policy of communicating the fact of low risk (reassurance) stands in danger of substituting a less sophisticated calculus of risk avoidance than is already reflected in an individual's choices. Fear of crime has its uses. If we did not worry about crime we would not close our windows when we leave the house or lock our doors. We would not avoid secluded alleyways or poorly lit streets at night. Simple precautions can reduce our risk of becoming a victim. However, the application of risk analysis to crime prevention is not always clear: it has been noted that households with fewer security devices tend to have less insurance, even though they may be living in relatively high crime areas (Budd, 1999). Poorer households are more likely to be found in a neighbourhood with high crime, but they are less likely to be able to afford added home security. This is the most plausible explanation of the high burglary victimization rates for the unemployed and identifies a target group which may need additional help to reduce the risk of being burgled.

\section{Repeat victimization}

Differential risks help to educate government, both national and local, about where it needs to invest resources to address crime. At the most local level, knowing that crimes are more likely to occur in badly designed housing estates with hidden alcoves and secluded walkways affords a lesson for architects and planners. The effect of lighting in reducing crime in public places (see Painter and Farrington (1999)) provides an important argument in favour of investing in better lighting. Local crime reduction partnerships, involving local councils, the police, the health service and a range of other agencies, need to understand the relative risks that are attached to particular circumstances. Section 17 of the Crime and Disorder Act 1998 imposes a statutory duty on local authorities in England and Wales to consider the effects of crime on all their decisions, which is clearly impossible without having information about relative risks.

Table 2 gives data about the distribution of crime victimization, showing that some are far more victimized than would be expected on the basis of a simple Poisson process. These data come from the Netherlands (see Kleemans (2001)). An analysis of data from international data sets from the United Nations and the International Crime Victimisation Survey illustrates that repeat victimization is high in all the countries measured (see Farrell and Bouloukos (2001)). For data from England and Wales on the topic, see Pease (1998).

Distributing crime reduction resources on the basis of prior victimization provides an elegant approach to a reduction in crime, for several reasons. No further information is required by the police beyond the fact that a call for police service has been received. Repetition, when it occurs, tends to occur quickly, although a degree of elevated risk persists over years. Thus a time-limited concentration of resources is worthwhile. 
Table 2. Observed and expected (Poisson) distribution of burglaries, Enschede 1987-1992

\begin{tabular}{|lrc|}
\hline Number of burglaries & Frequency & Expected frequency \\
\hline & & \\
0 & 53499 & 52981 \\
1 & 4732 & 5634 \\
2 & 579 & 300 \\
3 & 91 & 11 \\
$\geqslant 4$ & 24 & $<1$ \\
\hline
\end{tabular}

There are two possible reasons why the probability of victimization increases with prior victimization. In the first, victimization flags a place or person who is prone to victimization. In the second, the first event boosts the probability of a second, because the burglar knows what remains of value (or will be replaced by insurance); the assaultive husband knows that his wife will, having nowhere to go, put up with his attacks. The latter is one reason why it is particularly fitting that the police service measures its success in dealing with domestic violence not by the overall number of such incidents that they attend but by the number of repeat domestic incidents. If they must go back again, clearly the initial response (and their initial risk assessment) was inadequate. Modelling suggests that both processes are implicated (Tseloni and Pease, 2003).

\section{Shuffling crime around?}

There has been much debate in other contexts about whether reductions of risk by engineering or other physical means is offset by changes in behaviour (see for example Adams (1995)). This is called displacement when it refers to crime:

'There is little point in the policy-maker investing resources and effort into situational [crime] prevention if by doing so he merely shuffles crime from one area to the next but never reduces it. For this reason, the possibility of displacing crime by preventive intervention is a crucial issue for the policy maker' (Heal and Laycock (1986), page 123).

Displacement can induce a 'paralyzing extreme case pessimism' (Cornish and Clarke, 1987). Rene Hesseling reviewed all 55 published articles in which researchers specifically looked for evidence of displacement. He concluded that (Hesseling (1994), page 219)

'displacement is a possible, but not inevitable consequence of crime prevention. Further, if displacement does occur, it will be limited in size and scope. This conclusion is supported by other review studies on the topic.'

Offenders have limited 'travel to crime' ranges (see Wiles and Costello (1999)). This fact and other rational choice considerations also suggest that the extent of displacement will be limited (Cornish and Clarke, 1987; Bouloukos and Farrell, 1997).

In six of the studies that he reviewed, Hesseling (1994) found diffusion of benefits, which is the opposite of displacement and involves a reduction in crime extending beyond the boundaries of an initiative. Where this has been looked for specifically, it has often been found.

\section{What next?}

We know who is at risk, what they estimate their risks to be and how worried they are. We know that, as elections approach, concern about crime increases, presumably as political debate 
drives individual concerns (Surette, 1992). What has been missing from the crime area has been the kind of methodology, revealed preferences and the like, that is common in health policy, to inform resourcing of policing and criminal justice. Perhaps this has been because debates in crime are suffused by notions of blame. The more recent emphasis on how the supply of criminal opportunities may be regulated may herald a more systematic approach to the distribution of unavoidable hazard among citizens and the examination of heuristics and biases in judgments about crime risk informed by the tradition established by Kahneman et al. (1982). Daniel Kahneman and Amos Tversky, with their colleagues, identified circumstances in which people are risk averse and risk seeking, the circumstances in which they ignore statistical base rates and in which their judgments reflect such rates. Their examples tend to come from gambling and investment decisions, personality judgments and medical choices. To the writers' knowledge, decisions about life styles carrying varying risks of victimization have not featured in their empirical work, although some (probably safe) generalizations could be made about (for example) sentencing and discretionary release decisions. As a first stage, the replication of many of the classic Kahneman and Tversky studies using crime exemplars would provide a basis for understanding how perceptions of crime hazards develop.

\section{References}

Adams, J. (1995) Risk. London: University College London Press.

Bolling, K., Clemens, S., Phelps, A. and Smith, P. (2002) 2001 British Crime Survey: England and Wales Technical Report. London: British Market Research Bureau.

Bouloukos, A. C. and Farrell, G. (1997) On the displacement of repeat victimisation. In Rational Choice and Situational Crime Prevention (eds G. Newman, R. V. Clarke and S. G. Shoham). Aldershot: Dartmouth Press.

Budd, T. (1999) Burglary of domestic dwellings: findings from the British Crime Survey. Statistical Bulletin $18 / 01$. Home Office, London.

Cornish, D. B. and Clarke, R. V. (1987) Understanding crime displacement: an application of rational choice theory. Criminology, 25, 933-947.

Farrell, G. and Bouloukos, A. (2001) International overview: a cross-national comparison of rates of repeat victimisation. In Repeat Victimisation (eds G. Farrell and K. Pease). Monsey: Criminal Justice.

Heal, K. and Laycock, G. K. (1986) Situational Crime Prevention: from Theory into Practice. London: Her Majesty's Stationery Office.

Hesseling, R. B. P. (1994) Displacement: a review of the empirical literature. In Crime Prevention Studies 3 (ed. R. V. Clarke). Monsey: Willow Tree.

Kahneman, D., Slovic, P. and Tversky, A. (eds) (1982) Judgment under Uncertainty: Heuristics and Biases. New York: Cambridge University Press.

Kershaw, C., Chivite-Matthews, N., Thomas, C. and Aust, R. (2001) The 2001 British Crime Survey: first results, England and Wales. Statistical Bulletin 18/01. Home Office, London.

Kleemans, E. R. (2001) Repeat burglary victimisation: results of empirical research in the Netherlands. In Repeat Victimisation (eds G. Farrell and K. Pease). Monsey: Criminal Justice.

Mayhew, P. and Elliott, D. (1990) Self-reported offending, victimisation, and the British Crime Survey. Vict. Viol., 5, 83-96.

Painter, K. and Farrington, D. P. (1999) Street lighting and crime: diffusion of benefits in the Stoke-on-Trent project. In Surveillance of Public Space: CCTV, Street Lighting and Crime Prevention (eds K. Painter and N. Tilley). Monsey: Criminal Justice.

Pease, K. (1988) Judgements of crime seriousness: evidence from the 1984 British Crime Survey. Home Office Research and Planning Unit Paper 44. Home Office, London.

Pease, K. (1998) Repeat victimisation: taking stock. Crime Detection and Prevention Paper 90. Home Office, London.

Simmons, J. (2002) Crime in England and Wales 2001/2002. Statistical Bulletin 07/02. Home Office, London.

Surette, R. (1992) Media, Crime and Criminal Justice: Images and Realities. Pacific Grove: Brooks-Cole.

Tseloni, A. and Pease, K. (2003) Repeat victimisation: boost and flag explanations. Br. J. Criminol., 43, $196-212$.

Wikstrom, P.-O. and Loeber, R. (2000) Do disadvantaged neighborhoods cause well-adjusted children to become adolescent delinquents? Criminology, 38, 1201-1233.

Wiles, P. and Costello, A. (2000) The road to nowhere: the evidence for travelling criminals. Research Study 207. Home Office, London. 